\title{
Liability Analysis of Autonomous Vehicles Accidents
}

\author{
Cimo Xue ${ }^{1, *}$
}

\author{
${ }^{1}$ Yunnan University of Finance and Economics, Law school, Kunming, Yunnan 650000, China \\ *Corresponding author. Email: 1034878874@qq.com
}

\begin{abstract}
With the development of artificial intelligence, more and more autonomous vehicles have been put into production and will be on the roads within a couple of years, cutting congestion and delivering a big boost to road safety. But autonomous vehicles have already caused accidents and the innovation of autonomous vehicle are greatly outpacing legislation designed. This paper focuses on two fatal cases of accidents that autonomous vehicles caused and proposes some subjects that may be held responsible in the accidents. Then the author proposes five subjects of liability and possible charges from both civil law side and criminal law side in order to give some advice for future lawmaker. Solutions from before to after are also included to let subjects of liability to seek remedy.
\end{abstract}

Keywords: AI, Liability, Subject, Accident.

\section{INTRODUCTION}

Autonomous vehicles will undoubtedly usher in a new era for transportation. They ease the burdens of driving and make it safer. Yet in some cases, the technology has also created problems. Since the first fatal accident involving an Uber autonomous vehicles in Arizona, resulting in the unfortunate death of a pedestrian on the bicycle crossing the road, safety concerns and accountability regarding the use of autonomous vehicles became a hotly discussed issue. In this way, figuring out who is to blame for autonomous vehicles when they cause accidents becomes important since safety regulations and laws are still being written for autonomous vehicles but they are already on the road and causing accidents.

This paper can be divided into three parts, which are the description and analysis of existing problems, the possible responsible subjects and the solutions.

In the discussion of the existing problems, the author focuses on two examples of the accidents that autonomous vehicles caused. In the part of possible liability subjects, the author will propose some possible liability subjects and analyze them. In the solutions section, the author puts forward solutions for the autonomous stakeholder before and after the accidents. The research focuses on the subject who may bear the responsibility of autonomous vehicles' accidents. The research method of this paper is to analyze specific cases and search relevant papers to sort out the subject that may need to take responsibility. This paper is of great significance. In the process of artificial intelligence development, it can not only provide a responsibility subject for lawmakers, but also provide a way for AV stakeholders to seek relief.

\section{DESCRIPTION OF THE EXISTING PROBLEM}

According to BBC News and the New York Times, Elaine Herzberg is a woman who walked a bicycle across the road outside of the crosswalk in Tempe, Arizona, and was killed by an autonomous vehicle operated by Uber, which was believed to be the first pedestrian fatality involving self-driving technology. The car was in autonomous mode with a safety driver when it struck the victim. Video shows that the safety driver, Rafael Vasquez, was looking down from the road, and both of her hands were not on the steering wheel. However, most safety drivers are instructed to control the wheel because in this way they can have the ability to take over control of the vehicle immediately if an emergency happens. After a long investigation, the safety driver was founded at fault because she had been watching a television show when the emergency appeared.

In this case, the driver was charged with negligent homicide while the Uber company wasn't held 
responsible for the criminal charge because it is the driver who at fault. But if Uber company was aware that their autonomous vehicles have problems identifying barriers, pedestrians or something on the road and still put the autonomous vehicles on the road, maybe they should bare some responsibilities. And photos show that when the pedestrian crossed the road with a bike without using a crosswalk, maybe she is also at fault according to the law on the road traffic safety, which requires pedestrian to use a crosswalk when they cross the road. Apart from safety driver and pedestrian, maybe the designer is at fault. This is because the artificial intelligence that powered the autonomous vehicles doesn't safe enough since it can not process the image of fastmoving things. If the designer is at fault, should the local supervision department who acts as a supervisor deciding whether autonomous vehicles could be put on the road take responsibility?

Another fatal accident involving autonomous technology is Boeing 737 max aircraft. The Ethiopian airline crashed six minutes after takeoff, killing all 157 people aboard on 10 March 2019. According to Wikipedia, one minute after takeoff, the plane's automated software system known as MCAS (manoeuvring characteristics augmentation system) activated at the wrong time and forced the aircraft to dive toward the ground when the aircraft was supposed to climbing. The pilots failed to stop nosedive and then the plane crashed into a farm field.

When this happened, there was news with the headline "AI kills". But who has to take responsibility is still under investigation.

The cause of the accident is thought to be the design flaws of the flight control system called MACS. The system relied on data collected by a single sensor plays a role in determining the angle of the plane. The malfunction of this system had trouble identifying the angle and lead to the nosedive of the plane when the pilots were struggling to take over control and gain weight. In this way, some may hold that the automated MACS system is to blame. The author will give a deeper analysis of whether we could blame the automated system in the following part. But it's commonly accepted that the designer should be held responsible.

Some may contend that maybe the pilots should take responsibility. According to Ethiopian transport minister Dagmawit Moges, the crew "performed all the procedures repeatedly provided by the manufacturer and FAA but wasn't able to control the aircraft." But later report by US Transportation Safety Board found that the crew didn't react in the ways BOEING and FAA assumed they would. And the first officer was performed badly when the emergency happened. But whether the pilots are at fault isn't clear since the investigation into the accidents is still under way.

After two fatal crashes (the Lion Airline is the former one), Boeing company was under great fire from the society and was sued by relatives of the death. Relatives contend that Boeing hadn't done enough to make sure the design of the plane is safe after the lion air flight crashed into the sea off Indonesia.

What's more, the NTSB says that the simulator tests failed to incorporate the kinds of problems that could contribute to such a fatal emergency, which means that when the emergency happened, pilots were facing unencountered situation had not met in the simulator. As a result, they did not operate in the way Boeing had assumed they would. If Boeing company had alert and instruct the pilots how to react to different kinds of emergencies, maybe the accident will not happen.

And when it comes to FAA - federal aviation administration, should they held responsibility because they failed to decide whether the plane is safe and put them into commercial use.

In these cases, safety drivers (or pilots), pedestrian, company, designer, government, FAA may be responsible. But we should be aware that every case is different, we can't generalize. In the case of Uber, because both the safety driver and the pedestrian are at fault, the product liability of the manufacturer and the company can be basically excluded after proving that the quality of the Autonomous vehicles itself is fine. But in Boeing's case, a combination of factors that contributed to the crash since most air accidents is caused by a combination of technical problems and human error. In this case, we should analyze the situation from different perspective. It should also be noticed that as autonomous technology and vehicles become more widely put into the road, more subjects who should take responsibility will emerge. Since there is no current AI law to regulate the issue of autonomous vehicle accidents, the author will provide some suggested subjects of responsibility for future lawmakers. 


\section{SUBJECT OF RESPONSIBILITY}

\subsection{Pedestrian}

A driver(operator) cannot be held liable for hitting a pedestrian when the circumstances precluded the driver's awareness of the person in question and that person had the last definitive opportunity to avoid an incident.[1] Just as in Uber case above, if the operator wasn't at fault, the pedestrian should hold liability since she should have to use the crosswalk to cross the street.

\subsection{Operator}

In common law, the user of a ship or plane can be held liable for their negligent use of an autopilot system.[2] As in a conventional vehicle case, human errors are the most common sources of fault that causes an accident. But in the case of vehicles involving automated technology, the operator may not bear the fault if a system glitch happens in the full autonomous mode because the operator is not the cause of accident or injury. However, the manufacturer will always shift their liability to operator since the operator can always be shown to have various degrees of fault, which deserves the attention of future law makers. How to evaluate operator negligence should be analyzed by a court case by case.

\subsection{The Manufacturer-product Liability}

According to the Louisiana Products Liability Act, product liability arises in the case of defective design, manufacturing defect, or a failure to warn.[3]The statute further provides that adequate warnings about a product are considered in determining the degree of care shown by the manufacturer.[4] Consumers could allege that manufacturer or designer are liable and there is any defect in the autonomous vehicle. This approach which lets the autonomous vehicle manufacturer take too much risk of taking strict liability will hinder the development of automated technology. But this problem could be solved by the free market.[5] However, Volvo announced that it would "accept full liability whenever one of its cars is in autonomous mode." [6]

\subsection{The Owner-tort Liability}

Owner liability under common law results from one's duty to inspect his property and repair any defective condition that could cause harm to another.[7]
From a parallel perspective, the analysis of this problem could refer to how the law regulates in the past when new technology emerged. Taking the elevator for instance, it seems to be a comparable instance of a technology that its defect could subject its owner to hold liability. This is because elevators and autonomous vehicles are both created as technologies used to transport individuals, controlled by a human, and progressed to a more autonomous model.[8] The view that the owner should hold liability could be supported by the elevator case.

In this analysis, we should pay attention to the burden shift of proof. Liability for owners of autonomous vehicles shares similarities with that of masters or employers and owners of animals or buildings. No-fault liability would obviate the need for a plaintiff to prove a design defect or user error in an extremely advanced technological vehicle. In this way, the victim of a traffic accident would face an extremely unfavourable situation where the owner did nothing wrong and a manufacturer with exclusive knowledge of the systems and superior expertise.[9]

\subsection{The Autonomous Vehicles}

A court could hold the autonomous vehicle itself liable for its actions depend on whether the autonomous vehicle can be treated as a juridical person.[10]

Weak AI should not be recognized as legal subjects. Firstly, from a theoretical point of view, weak AI vehicles lack the thinking and processing mode necessary for legal subjects, and their compliance with legal norms is mechanical and uncreative. Even if it is endowed with an electronic personality, it is also a legal fictitious personality. Secondly, from a practical point of view, the vehicle involved in the accident not only has no sense of autonomy, but even after the feedback, it has no right to choose the right decision, which is more like the semi-finished product of strong artificial intelligence or the front-end of processing.[11]

Strong AI can form its own cognition of external things through autonomous learning. They should bear criminal responsibility if they are self-conscious about the implementation of their criminal acts. [12]And strong AI may even violate the "three principles of robotics"[13] to commit other crimes. Therefore, endowing them with legal qualifications can improve the regulation of their responsibilities. But how to punish them attracts concern.

There are many possible subjects of responsibility. If we make a more detailed analysis, maybe when the 
passenger mistakenly started an artificial intelligence program to cause a car accident, the passenger may also become the subject of responsibility.

When it comes to penalty, a subject of responsibility who violates Civil law could pay compensation while a subject of responsibility who infringes criminal law may be sentenced to prison which needs to be analyzed case by case.

\section{SOLUTION}

\subsection{Solutions Adopted Before Accident}

Government should set market access standards based on research and test to determine whether an autonomous vehicle is well-equipped and could be put into the road. The government should also set up a regulatory mechanism to know and deal with accidents when they happen.

Building transport systems suitable for autonomous vehicle operation such as precise digital maps or real-time data, in order to increase road safety and accelerate the flow of transportation [14]

But If some errors occur in this situation, traffic congestion and accidents will happen. In this circumstance, those who hold liability should be fixed. However, creating a more identifiable road design could be useful.

It's high time for lawmakers to build AI related law as innovation of autonomous technology is greatly outpacing legislation designed.[15] The author of the paper has already numerated some possible subjects of responsibility, lawmakers could also use parallel methods to make AI law.

Designers and manufacturers should create safer and smarter autonomous vehicles. When an accident happens, the dashcam or related systems could know the status of the autonomous in order to determine who is to blame.

\subsection{Solutions Adopted After Accident}

We could place liability on the insurer to pay compensation for death, personal injury, and property that autonomous vehicle caused when it is selfdriving according to a bill The United Kingdom attempted to pass. [16]

However, this bill is far from perfect because it does not cover damage to the autonomous vehicle and when both injured parties show contributory negligence. [17] This is where future lawmakers could do better.

\section{CONCLUSION}

With the development of artificial intelligence, $\mathrm{AV}$ is already being produced and used by various tech giants, which inevitably causes some accidents. In this case, it is especially important to fill the legal gap. The author can only analyze the subject that may bear the responsibility based on existing cases, so as to provide reference for future law makers. As for the future application of these laws to practical problems, it is up to legal practitioners to analyze the specific problems case by case.

\section{AUTHORS' CONTRIBUTIONS} Xue.

This paper is independently completed by Cimo

\section{ACKNOWLEDGMENTS}

I would like to acknowledge Professor Sonia Katyal for giving me the suggested topic of my paper and guidance in law as well as paper outline with my TA Yuan. I acknowledge my thesis teacher for helping me optimize the paper. Without their help, this paper would not have been completed so smoothly.

\section{REFERENCES}

[1] see 92 so. 2d. at 596. -from En Garde: A Civil Law Approach to Autonomous Vehicle Liability Under Louisiana Law?

[2] 129.id.at 140-41-from En Garde: A Civil Law Approach to Autonomous Vehicle Liability Under Louisiana Law?

[3] En Garde: A Civil Law Approach to Autonomous Vehicle Liability Under Louisiana Law?

[4] id.; see also Felice v. Valleylab, Inc., 520 So. 2d 920,926(La. App.3 Cir.1987) En Garde: A Civil Law Approach to Autonomous Vehicle Liability Under Louisiana Law?

[5] Driving The Future: Antiquated Treaties, Unintended Effects, And Inconsistent Implementation Of Autonomous Vehicle Law.

[6] Press Release, Volvo Car Grp., US Urged to Establish Nationwide Federal Guidelines for Autonomous Driving (Oct. 7, 2015), https://www.media.volvocars.com/global/engb/ media/pressreleascs/167975/us-urged-toestablish-nationwide-federal-guidelines- 
forautonomous-driving [https://perma.cc/97FM4BYH].

[7] King, supra note 79, at 136. En Garde: A Civil Law Approach to Autonomous Vehicle Liability Under Louisiana Law?

[8] see.id.En Garde:A Civil Law Approach to Autonomous Vehicle Liability Under Louisiana Law?

[9] See WILMOT \&GREENSWORD, supra note6, at 19(discussing the predicted shift from insuring people to insuring products)

[10] S.M. Solaiman, Legal Personality of Robots, Corporations, Idols and Chimpanzees: A Quest for Legitimacy, 25 ARTIFICIAL INTELLIGENCE \& L.ONLINE 155,17374(2017)

[11] Criminal response to traffic accident caused by artificial intelligence

[12] Liu Xianquan: The Reconstruction of Criminal Responsibility and Penalty System in the Age of Artificial Intelligence

[13] By the American science fiction writer amosif put forward

[14] Woollaston \& Moldrich, supra note 15.- AS THE ROLE OF THE DRIVER CHANGES WITH AUTONOMOUS VEHICLE TECHNOLOGY,SOO, TOO, MUST THE LAW CHANGE

[15] Marcus E. Johnson, The Drive for Autonomous Vehicles: Idaho's Race To Catch Up, 59 ADVOC.28,28(2016)

[16] Vehicle Technology and Aviation Bill 2016-17, HC Bill [143] cl. 2 (UK), https://publications.parliament.uk/pa/bills/cbill/2 016-2017/0143/cbill_2016-

20170143_en_2.htm\#ptl-llg2

[https://perma.cc/2Z6F-EZUE].

[17] id. [143] cl. 3.-Driving The Future: Antiquated Treaties,Unintended Effects, And Inconsistent Implementation Of Autonomous Vehicle Law 